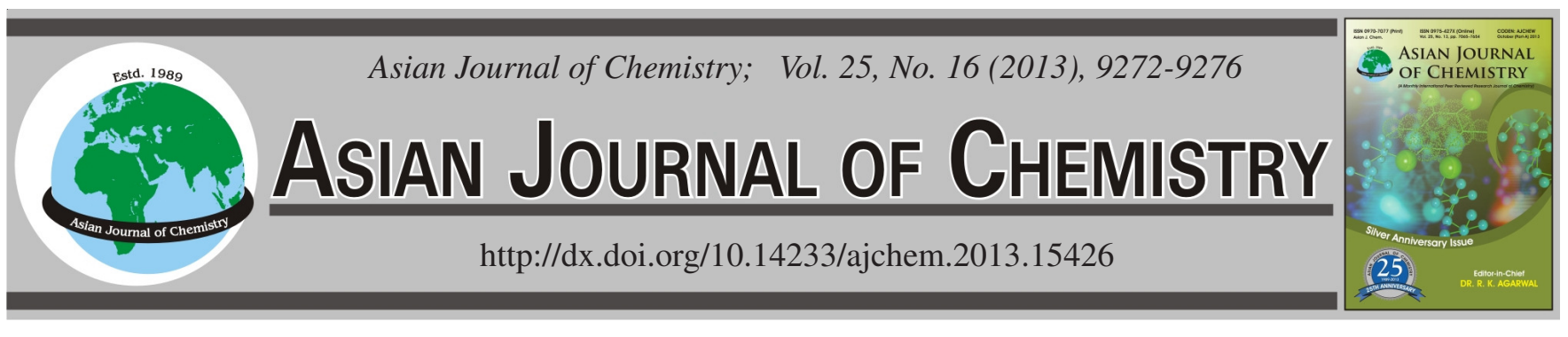

\title{
Spectrophotometric and Spectrofluorimetric Methods for the Determination of Gemifloxacin Mesylate in its Pure and Dosage Forms using Eosin
}

\author{
Salma Ali Al-Tamimi
}

Department of Chemistry, College of Science, King Saud University, P.O. Box 22452, Riyadh 11495, Saudi Arabia

Corresponding author: E-mail: satamimi@ksu.edu.sa

\begin{abstract}
Spectrophotometric and spectrofluorimetric methods were developed for the determination of gemifloxacin mesylate (GFX) in dosage forms. The spectrophotometric method (method I) is based on formation of ternary complex with eosin at $543 \mathrm{~nm}$ in acetate buffer of $\mathrm{pH}$ 4. The absorbance-concentration plot is rectilinear over the range $1-10 \mu \mathrm{g} / \mathrm{mL}$ with LOD of $0.157 \mu \mathrm{g} / \mathrm{mL}$ and LOQ of $0.476 \mu \mathrm{g} / \mathrm{mL}$. The spectrofluorimetric method (method II) is based on the quantitative quenching effect of gemifloxacin mesylate on the native fluorescence of eosin at the same $\mathrm{pH}$. The quenching of the fluorescence of eosin was measured at $544 \mathrm{~nm}$ after excitation at $337 \mathrm{~nm}$. The fluorescenceconcentration plot is rectilinear over the range $0.6-4 \mu \mathrm{g} / \mathrm{mL}$ with LOD of $0.108 \mu \mathrm{g} / \mathrm{mL}$ and LOQ of $0.328 \mu \mathrm{g} / \mathrm{mL}$. The proposed methods were successfully applied to the analysis of tablets of the drug. Statistical comparison of the results with those of the reference method revealed good agreement and proved that there were no significant differences in the accuracy and precision between the two methods respectively.
\end{abstract}

Key Words: Gemifloxacin mesylate, Eosin, Spectroflurimetry, Spectrophotometry, Dosage forms.

\section{INTRODUCTION}

Gemifloxacin (Fig. 1) is a fourth generation synthetic broad-spectrum fluorinated quinolone antibacterial agent for oral administration. It is present in two forms; either as free gemifloxacin base or as gemifloxacin mesylate salt. Gemifloxacin has a broad-spectrum activity against both Gram-negative and Gram-positive microorganisms. The main advantages of gemifloxacin over the older agents of fluoroquinolones is retaining the excellent activity against Gramnegative bacilli and improving Gram-positive activity (including S. pneumoniae and Staphylococcus aureus). Therefore, gemifloxacin was approved by the food and drug administration in April 2003 for treatment of acute bacterial exacerbation of chronic bronchitis, mild-to-moderate pneumonia multidrug resistant S. pneumoniae as well as community-acquired pneumonia ${ }^{1}$.<smiles>CO/N=C1\CN(c2nc3c(cc2F)c(=O)c(C(=O)O)cn3C2CC2)CC1CN</smiles>

Fig. 1. Structure of Gemifloxacin Mesylate
The published methods for the determination of gemifloxacin included high-performance liquid chromatography $^{2-10}$, high-performance liquid chromatography-tandem mass spectrometry ${ }^{11,12}$, voltammetry ${ }^{13}$, potentiometry ${ }^{14}$, capillary electrophoresis ${ }^{15,16}$, spectrophotometry ${ }^{17-23}$, chemiluminescence $^{24}$ and spectrofluorimetry ${ }^{25}$.

Due to their low cost and inherent simplicity spectrophotometry and spectrofluorimetry are the techniques of choice in research laboratories, hospitals and pharmaceutical industries. Accordingly, the present work was aimed at developing new simple, sensitive and selective spectrofluorimetric and spectrophotometric procedures for determination of gemifloxacin mesylate in dosage forms.

The literature review showed that palladium(II) ion and eosin are the widely used agents to form the ternary complexes with the various drugs ${ }^{26-28}$. All described methods are marked by good sensitivity, precision and, accuracy. The aim of this research was to investigate the reaction between gemifloxacin mesylate, palladium (II) ion and eosin with the ternary complex formation. The methyl cellulose was used as a surfactant to increase the solubility and intensity of the complex formed. The optimum conditions ( $\mathrm{pH}$, concentrations of reagents, temperature and time of heating, etc.) were established before the application of the method to the analysis of the drug as its bulk and pharmaceutical preparation. The proposed method 
is simple, sensitive, accurate and relatively low cost. It can be applied in quality control laboratories methods for determination of gemifloxacin mesylate.

\section{EXPERIMENTAL}

An UV-visible spectrophotometer model Ultrospec 2000Pro (Biochrom, England) with matched $1 \mathrm{~cm}$ quartz cells was used for all spectrophotometric measurements.

Fluorescence intensity was measured on a Perkin-Elmer model LS-55 luminescence spectrometer (UK), equipped with a $150 \mathrm{~W}$ xenon arc lamp, grating excitation and emission monochromators and a Perkin-Elmer recorder. Slit widths for excitation and emission monochromators were set at 5 and $7 \mathrm{~nm}$, respectively.

All reagents used were of Analytical reagent grade and distilled water was used throughout the study:

Gemifloxacin mesylate was kindly supplied from Saudi Pharmaceutical Industries and Medical Appliances Corporation, Al-Qassim Pharmaceutical Plant (SPIMACO) Saudi Arabia. (Factive ${ }^{\circledR} 320 \mathrm{mg} /$ tablet) was provided by (SPIMACO) Saudi Arabia. Eosin (Merck, Darmstadt, Germany) was prepared as $1.0 \times 10^{-3} \mathrm{M}$, aqueous solution. Palladium(II) chloride (Sigma-Aldrich) was prepared as $1 \times 10^{-3} \mathrm{M}$ solution by dissolving about $17.75 \mathrm{mg}$ of $\mathrm{PdCl}_{2}$ in $1 \mathrm{~mL}$ of hydrochloric acid, with the aid of heat, followed by the addition of $50 \mathrm{~mL}$ of boiled water and diluting to $100 \mathrm{~mL}$ with distilled water; Methyl cellulose (Prolabo, France), $0.5 \%$ w/v aqueous solution, prepared by dissolving the appropriate amount in hot water $\left(80{ }^{\circ} \mathrm{C}\right.$ ) with stirring for $10 \mathrm{~min}$, then cooled to $5{ }^{\circ} \mathrm{C}$ for 30 min. Acetate buffer ( $\mathrm{pH} 4$ ), prepared by mixing $0.2 \mathrm{M}$ acetic acid solution and $0.2 \mathrm{M}$ sodium acetate solution and adjusting the $\mathrm{pH}$ using $\mathrm{pH}$ Meter.

Standard solutions: Stock solution of gemifloxacin mesylate was prepared by dissolving $10 \mathrm{mg}$ of the drug in 100 $\mathrm{mL}$ of distilled water. This solution was further diluted with the same solvent to obtain a working solution. The solution were stable for 2 weeks when kept in the refrigerator and protected from light.

Spectrophotometric method (method I): Aliquots of gemifloxacin mesylate covering the working concentration range $(1-10 \mu \mathrm{g} / \mathrm{mL})$ were transferred into a series of $25 \mathrm{~mL}$ volumetric flask. A $1 \mathrm{~mL}$ of $0.5 \%$ methyl cellulose solution, $2 \mathrm{~mL}$ of acetate buffer solution $(\mathrm{pH} 4), 1 \mathrm{~mL}$ of $1.0 \times 10^{-3} \mathrm{M}$ eosin solution and $1 \mathrm{~mL}$ of $1.0 \times 10^{-3} \mathrm{M}$ palladium(II) chloride solution were added to the flasks. The mixture was diluted to volume with water, homogenized by shaking and immersed in a warm water-bath $\left(70^{\circ} \mathrm{C}\right)$ for $20 \mathrm{~min}$. The solution was then cooled to room temperature and its absorbance was measured at $543 \mathrm{~nm}$ against an appropriate blank prepared simultaneously.

Spectrofluorimetric method (method II): The same procedure adopted for spectrophotometric method was followed after dilution of the standard solution to obtain the working concentration range of $0.6-4 \mu \mathrm{g} / \mathrm{mL}$. The fluorescence intensity of the resulting solution was measured at $544 \mathrm{~nm}$ after excitation at $337 \mathrm{~nm}$. The difference in the fluorescence intensity $(\Delta \mathrm{F})$ was plotted vs. the final concentration of the drug $(\mu \mathrm{g} / \mathrm{mL})$ to get the calibration curve.
Tablet treatment: The total content of ten tablets was ground to a fine powder. A weighed quantity of the powdered tablets equivalent to $10 \mathrm{mg}$ of gemifloxacin mesylate was transferred into $100 \mathrm{~mL}$ volumetric flask and the flask was sonicated for $30 \mathrm{~min}$. The solution was diluted to volume with distilled water, mixed and filtered. Aliquots covering the working concentration range were transferred into a series of $25 \mathrm{~mL}$ volumetric flasks. The procedure described under construction of the calibration curve was performed. The nominal content of the tablets was calculated using the calibration graph or the corresponding regression equation.

\section{RESULTS AND DISCUSSION}

The fact that the pyridinic carboxylic acid derivatives form stable metal chelates with different cations suggested the possibility of the utilization of this phenomenon for increasing the sensitivity of both spectrophotometric and fluorimetric measurements, through the formation of a stable ternary complex of acid-palladium may be expressed as drug-Pd(II)-eosin $(1: 1: 1)$ in the presence of methyl cellulose ${ }^{26}$. In the present study, gemifloxacin mesylate was found to form an ion pair red complex with eosin at $\mathrm{pH} 4$ with maximum absorbance at $543 \mathrm{~nm}$ (Fig. 2). The formed complex is mainly due to the electrostatic interaction between the studied drug and anionic functional group of eosin under acidic $\mathrm{pH}$. The formed ion pair complex is not fluorescent; therefore, the decrease in the fluorescence of eosin upon the addition of the drug was the basis fot the spectrofluorimetric measurement at $544 \mathrm{~nm}$ after excitation at $337 \mathrm{~nm}$ (Fig. 3).

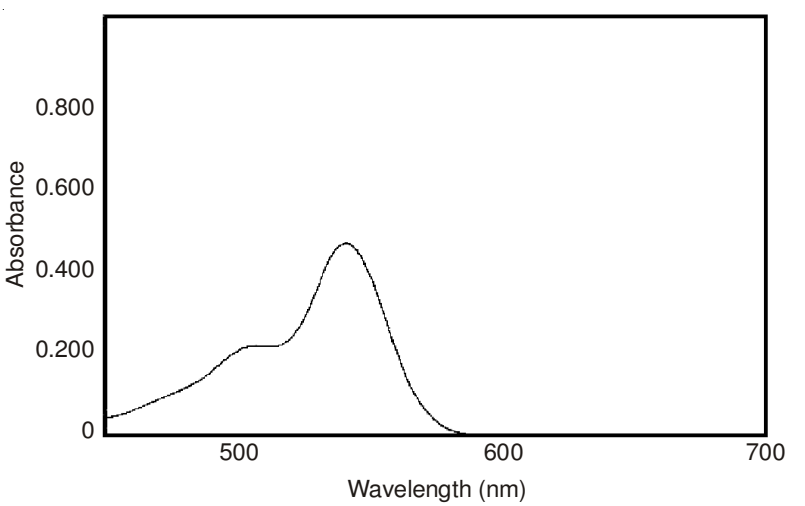

Fig. 2. Absorption spectra of reaction product of gemifloxacin mesylate $(5 \mu \mathrm{g} / \mathrm{mL})$

Optimization of experimental conditions: The spectrophotometric and spectrofluorimetric properties of the product as well as the various experimental parameters affecting its development and stability were particularly analyzed and optimized. Some factors were changed individually; others were kept constant. These factors include: volume of eosin, volume of Pd(II), type of buffer, volume of buffer and time of heating.

Effect of volume of eosin: The effect of the eosin concentration on the absorbance of the ternary complex formed was studied. The optimum result was obtained using $1 \mathrm{~mL}$ of $1 \times 10^{-3} \mathrm{M}$ of eosin (Fig. 4).

Effect of volume of Pd (II): The influence of Pd(II) was studied using increasing volumes of $1 \times 10^{-3} \mathrm{M} \mathrm{Pd}(\mathrm{II})$. The optimum result was obtained using $1 \mathrm{~mL}$ (Fig. 5). 


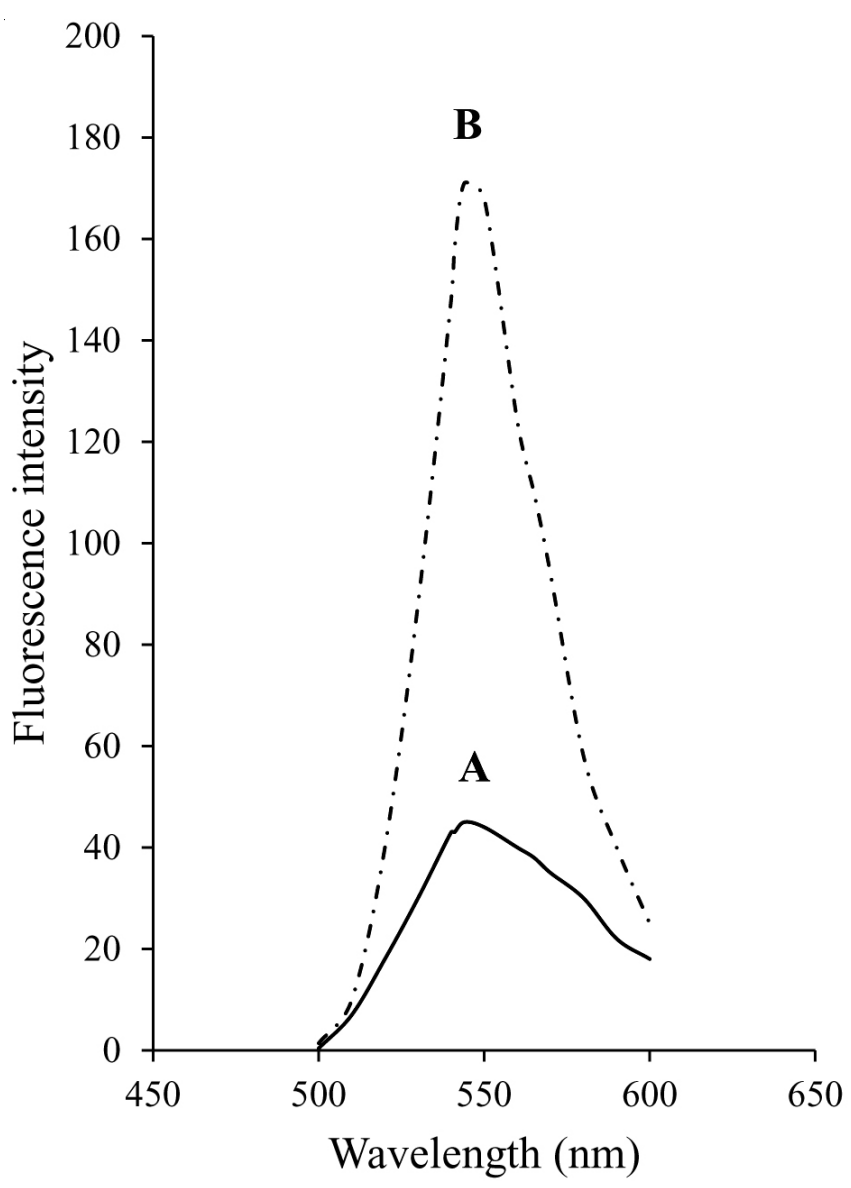

Fig. 3. Emission spectra of: (A) Reaction product (B) Blank of gemifloxacin mesylate $(3 \mu \mathrm{g} / \mathrm{mL})$

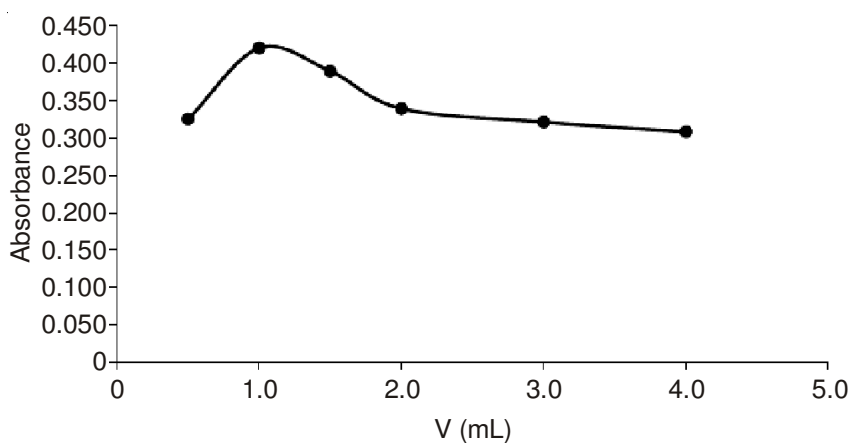

Fig. 4. Effect of volume of eosin $\left(1.0 \times 10^{-3} \mathrm{M}\right)$ on the absorbance of the reaction product of gemifloxacin mesylate $(5 \mu \mathrm{g} / \mathrm{mL})$

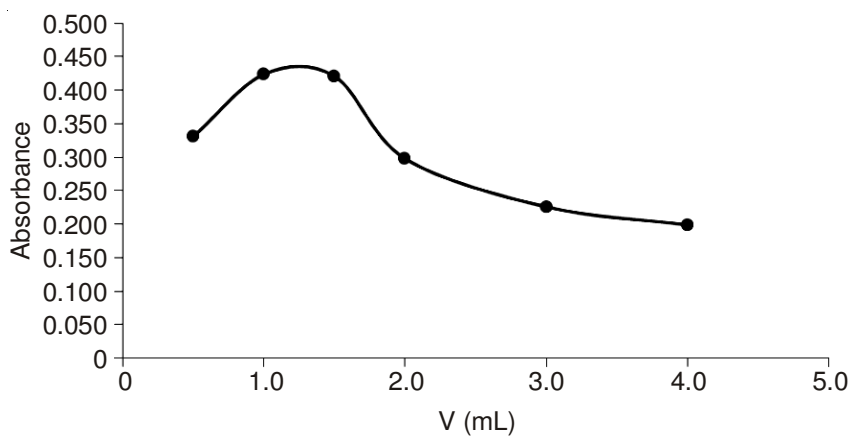

Fig. 5. Effect of volume of $\mathrm{Pd}(\mathrm{II})\left(1.0 \times 10^{-3} \mathrm{M}\right)$ on the absorbance of the reaction product of gemifloxacin mesylate $(5 \mu \mathrm{g} / \mathrm{mL})$
Effect of pH: The absorbance of the drug-Pd(II)-eosin complex solution was investigated over the $\mathrm{pH}$ range 3.6-12.32. The optimum absorbance was achieved at $\mathrm{pH} 4$ using $2 \mathrm{~mL}$ of acetate buffer (Fig. 6).

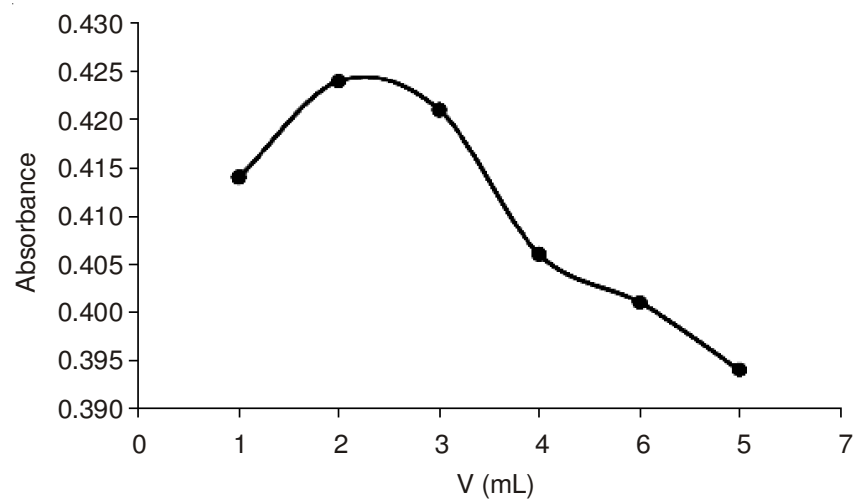

Fig. 6. $\mathrm{pH}$ influence on the absorbance of the reaction product of gemifloxacin mesylate $(5 \mu \mathrm{g} / \mathrm{mL})$

Effect of methyl cellulose volume: Maximum and constant absorbance was obtained with $1 \mathrm{~mL}$ of $0.5 \%$, w/v methyl cellulose (Fig. 7).

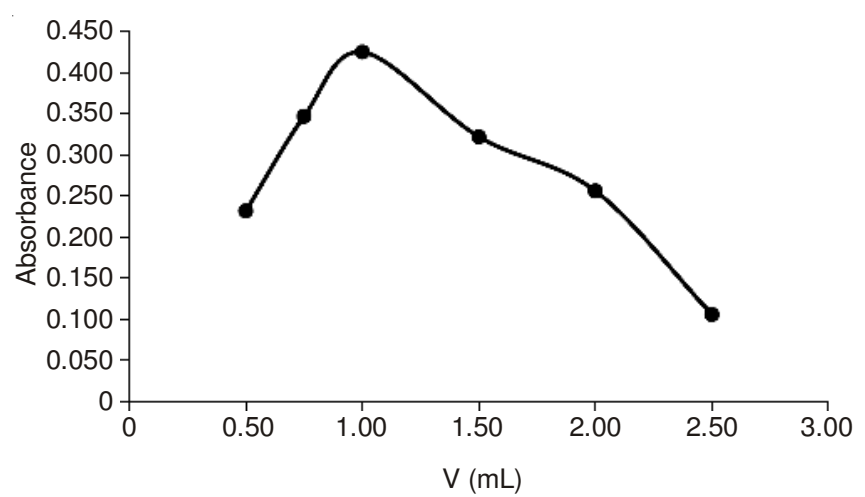

Fig. 7. Effect of volume of methyl cellulose $(0.5 \% \mathrm{w} / \mathrm{v})$ on the absorbance of the reaction product of gemifloxacin mesylate $(5 \mu \mathrm{g} / \mathrm{mL})$

Effect of temperature and heating time: In order to examine the effect of temperature and heating time on the formation rate and on the absorbance of the drug-Pd(II)-eosin ternary complex, the above-mentioned formation was carried out at different temperatures (room temperature, 40, 50, 60, 70 and $80^{\circ} \mathrm{C}$ ) using a thermostated water-bath for periods ranging from 5 to $40 \mathrm{~min}$. Maximum and constant absorbance was obtained at $70^{\circ} \mathrm{C}$ after $20 \mathrm{~min}$ (Figs. 8 and 9).

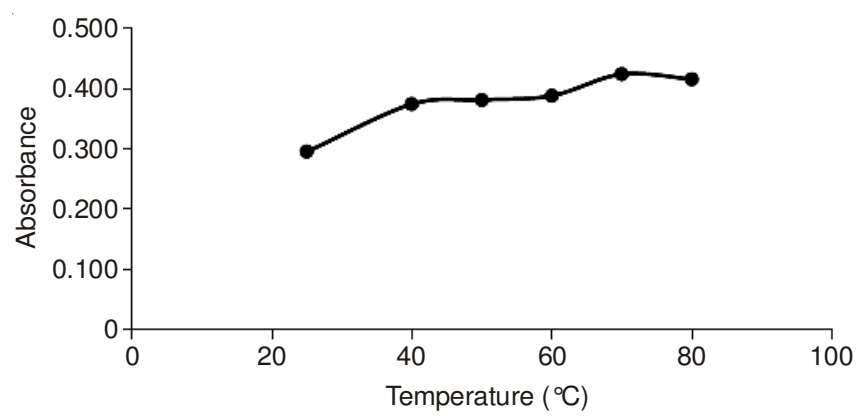

Fig. 8. Effect of temperature on the absorbance of the reaction product of gemifloxacin mesylate $(5 \mu / \mathrm{mL})$ 


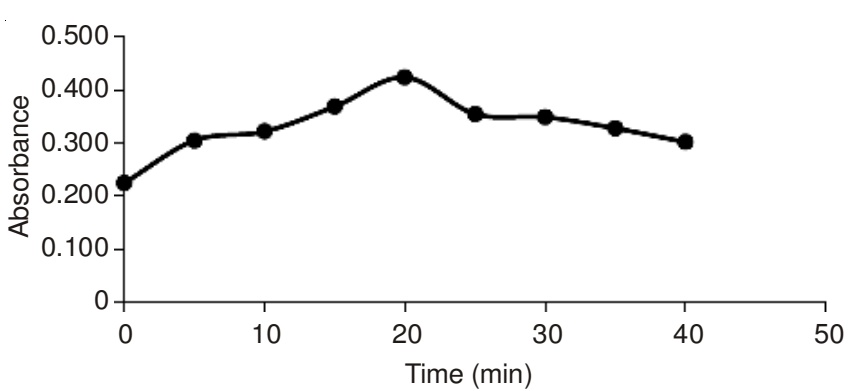

Fig. 9. Effect of heating time on the absorbance of the reaction product of gemifloxacin mesylate $(5 \mu \mathrm{g} / \mathrm{mL})$

Validation of the method: The validity of the proposed methods were tested for linearity, limit of detection, limit of quantitation, accuracy, precision and robustness.

Linearity: Under the described experimental conditions, the calibration graphs for the both methods were constructed by plotting the absorbance value in method I or difference in the fluorescence intensity $(\Delta \mathrm{F})$ in method II $v s$. concentration in $\mu \mathrm{g} /$ $\mathrm{mL}$. The regression plots showed a linear dependence of $\Delta \mathrm{F}$ and absorbance values on the drug concentrations over the range cited in Table-1. Regression equations, intercepts, slopes and correlation coefficients for the calibration data are presented in Table-1.

TABLE-1

PERFORMANCE DATA FOR THE PROPOSED METHODS FOR DETERMINATION OF GEMIFLOXACIN MESYLATE

\begin{tabular}{lcc}
\hline \multicolumn{1}{c}{ Parameters } & $\begin{array}{c}\text { Spectro- } \\
\text { photometric } \\
\text { method }\end{array}$ & $\begin{array}{c}\text { Spectro- } \\
\text { fluorimetric } \\
\text { method }\end{array}$ \\
\hline Concentration range $(\mu \mathrm{g} / \mathrm{mL})$ & $1-10$ & $0.6-4$ \\
$\mathrm{LOD}(\mu \mathrm{g} / \mathrm{mL})$ & 0.157 & 0.108 \\
$\mathrm{LOQ}(\mu \mathrm{g} / \mathrm{mL})$ & 0.476 & 0.328 \\
Correlation coefficient $(\mathrm{r})$ & 0.9998 & 0.9995 \\
Slope & 0.084 & 36.417 \\
Intercept & 0.013 & 19.107 \\
Standard deviation of the intercept $\left(\mathrm{S}_{\mathrm{a}}\right)$ & 0.004 & 1.193 \\
Standard deviation of the slope $\left(\mathrm{S}_{\mathrm{b}}\right)$ & 0.001 & 0.472 \\
\hline
\end{tabular}

Limit of quantification and limit of detection: The limit of quantification was determined by establishing the lowest concentration that can be measured according to ICH Q2 (R1) recommendation $\mathrm{s}^{29}$ below which the calibration graph is nonlinear. The limit of detection (LOD) was determined by evaluating the lowest concentration of the analyte that can be readily detected. The results were summarized in Table-1.

LOQ and LOD were calculated according to the following equations:

$$
\begin{aligned}
\mathrm{LOQ} & =10 \mathrm{~S}_{\mathrm{a}} / \mathrm{b} \\
\mathrm{LOD} & =3.3 \mathrm{~S}_{\mathrm{a}} / \mathrm{b}
\end{aligned}
$$

where, $S_{a}$ is the standard deviation of the intercept of regression line and $b$ is the slope of the regression line.

Accuracy and precision: Statistical analysis ${ }^{30}$ of the results obtained by the proposed and reported methods ${ }^{20}$ using student's t-test and variance ratio F-test showed no significant differences between them regarding accuracy and precision, respectively (Table-2). The small value of relative standard deviation, indicates high precision of the method for quantitative determination of gemifloxacin mesylate. Moreover, the good percentage recoveries confirms excellent accuracy.
TABLE-2

APPLICATION OF THE PROPOSED AND COMPARISON METHODS TO THE DETERMINATION OF GEMIFLOXACIN MESYLATE IN PURE FORM AND ITS PHARMACEUTICAL

\begin{tabular}{|c|c|c|c|}
\hline & \multicolumn{2}{|c|}{ Proposed methods } & \multirow[b]{2}{*}{$\begin{array}{l}\text { Reported } \\
\text { method }^{20}\end{array}$} \\
\hline & $\begin{array}{l}\text { Spectrophotometric } \\
\text { method }\end{array}$ & $\begin{array}{c}\text { Spectrofluorimetric } \\
\text { method }\end{array}$ & \\
\hline \multicolumn{4}{|l|}{ Pure form } \\
\hline Mean \pm SD & $99.57 \pm 1.209$ & $99.29 \pm 1.120$ & $99.50 \pm 0.747$ \\
\hline $\mathrm{N}$ & 6 & 6 & 6 \\
\hline$\%$ RSD & 1.214 & 1.128 & 0.751 \\
\hline t-test & $0.121(2.228)^{*}$ & $0.382(2.228)^{*}$ & \\
\hline F-test & $2.60(5.05)^{*}$ & $2.589(5.05)^{*}$ & \\
\hline \multicolumn{4}{|c|}{ Factive ${ }^{\circledR} 320 \mathrm{mg} /$ tablet } \\
\hline Mean \pm SD & $99.45 \pm 0.439$ & $100.240 \pm 0.586$ & $99.50 \pm 0.361$ \\
\hline $\mathrm{N}$ & 3 & 3 & 3 \\
\hline$\%$ RSD & 0.441 & 0.585 & 0.363 \\
\hline t-test & $0.152(2.776) *$ & $1.865(2.776)^{*}$ & \\
\hline F-test & $1.484(19) *$ & $2.641(19)^{*}$ & \\
\hline
\end{tabular}
DOSAGE FORM

*Figures in parentheses are the tabulated $\mathrm{t}$ and $\mathrm{F}$ values at confidence limits $95 \%^{30}$

Robustness of method: The robustness of the proposed methods was demonstrated by the constancy of the absorbance and the difference in the fluorescence intensity $(\Delta \mathrm{F})$ with the minor changes in the experimental parameters such as $\mathrm{pH} 4 \pm$ 0.2 and change in the volume of eosin \pm 0.2 . These minor changes that may take place during the experimental operation didn't greatly affect the absorbance or fluorescence values of the reaction.

\section{Conclusion}

Two new spectrophotometric and spectrofluorimetric methods for the determination of gemifloxacin mesylate in dosage forms are presented. They are simple, rapid, reproducible, economic, highly sensitive and do not require tedious extraction. The statistical data represent the suitability and reproducibility of the proposed methods for routine analysis in the quality control laboratories.

\section{ACKNOWLEDGEMENTS}

This project was supported by King Saud University, Deanship of Scientific Research, College of Science Research Center.

\section{REFERENCES}

1. B.M.H. Al-Hadiya and A.M.M. Mahmoud, Profiles of Drug Substances, Excipients and Related Methodology, 36, 151 (2011).

2. B.M.H. Al-Hadiya, A.A. Khady and G.A.E. Mostafa, Talanta, 83, 110 (2010).

3. U.S. Chakrabarty, A. Das, U. Bhaumik, B. Chatterjee, A. Ghosh, A. Bose, P. Sengupta, U. Nandi and T.K. Pal, Chromatographia, 69, 853 (2009).

4. M. Kaiser, L.D. Gruenspan, T. Dalla Costa and L. Tasso, J. Chromatogr. B: Anal. Technol. Biomed. Life Sci., 879, 3639 (2011).

5. R.N. Rao, C.G. Naidu, K.G. Prasad, R. Padiya and S.B. Agwane, Biomed. Chromatogr., 26, 1534 (2012).

6. P.N. Ranjane, S.V. Gandhi, S.S. Kadukar and K.G. Bothara, Chromatographia, 71, 1113 (2010).

7. A.R. Rote and S.P. Pingle, J. Chromatogr. B: Anal. Technol. Biomed. Life Sci., 877, 3719 (2009).

8. R.N. Rao, C.G. Naidu, K.G. Prasad and R. Narasimha, Biomed. Chromatogr., 25, 1222 (2011). 
9. N. Sultana, M.S. Arayne, S. Shamim, M. Akhtar and S. Gul, J. Brazil. Chem. Soc., 22, 987 (2011).

10. L.D. Gruenspan, M. Kaiser, F.K. Hurtado, T. Dalla Costa and L. Tasso, Chromatographia, 75, 253 (2012).

11. E. Doyle, S.E. Fowles, D.F. McDonnell, R. McCarthy and S.A. White, J. Chromatogr. B: Anal. Technol. Biomed. Life Sci., 746, 191 (2000).

12. B. Roy, A. Das, U. Bhaumik, A.K. Sarkar, A. Bose, J. Mukharjee, U.S Chakrabarty, A.K. Das and T.K. Pal, J. Pharm. Biomed. Anal., 52, 216 (2010).

13. R. Jain and J.A. Rather, Colloids Surf. B, 83, 340 (2011).

14. A.M. Al-Mohaimeed, S.A. Al-Tamimi, N.A. Alarfaj and F.A. Aly, Int. J. Electrochem. Sci., 7, 12518 (2012).

15. A.A. Elbashir, B. Saad, A. Salhin, M. Ali, K.M.M. Al-Azzam and H.Y. Aboul-Enein, J. Liq. Chromatogr. Rel. Technol., 31, 1465 (2008).

16. V.F. Tavares, D.C.S. Patto, A.K. Singh, M.S. Aurora-Prado, E.R.M Kedor-Hackmann and M.I.R.M. Santoro, Latin Am. J. Pharm., 30, 746 (2011).

17. D. Madhuri, K. Chandrasekhar, N. Devanna and G. Somasekhar, Int. J. Pharma Sci. Res., 1, 222 (2010).
18. C.S. Paim, F. Fuehr, M. Steppe and E.E. Scherman Schapoval, Quim. Nova, 35, 193 (2012)

19. M.V. Krishna and D.G. Sankar, E.-J. Chem., 5, 515 (2008).

20. R.R. Ambadas and P.P. Sunita, E.-J. Chem., 7, S344 (2010).

21. D. Jyothirmayee, G.S.S. Babu and G.D. Rao, Asian J. Chem., 22, 1634 (2010).

22. S. Ganapathy, G.V.H. Raju, D.G. Sankar and P.Y. Naidu, Asian J. Chem., 21, 6508 (2009).

23. M.V. Krishna and D.G. Sankar, E.J. Chem., 5, 493 (2008).

24. F. Zhao, W.-H. Zhao and W. Xiong, Luminescence, 28, 108 (2012).

25. S.E.K. Tekkeli and A. Onal, J. Fluorescence, 21, 1001 (2011).

26. A.F.M. El Walily, S.F. Belal and R.S. Bakry, J. Pharm. Biomed. Anal., 14, 561 (1996).

27. N. El-Enany, IL Farmaco, 59, 63 (2004).

28. H.E. Abdellatef, Spectrochimica Acta A, 66, 701 (2007).

29. I.C.H.H.T. Guideline, IFPMA: Geneva (2005)

30. J.C. Miller, Statistics for Analytical Chemistry, Ellis Horwood PTR Prentice Hall, New York, edn. 3 (1993). 